\title{
Precise Alignment of Individual Single-Walled Carbon Nanotube Using Dielectrophoresis Method for Development and Fabrication of pH Sensor
}

\author{
U. Hashim, Foo Wah Low, and Wei-Wen Liu \\ Institute of Nano Electronic Engineering (INEE), Universiti Malaysia Perlis (UniMAP), 01000 Kangar, Perlis, Malaysia \\ Correspondence should be addressed to U. Hashim; uda@unimap.edu.my
}

Received 6 August 2013; Accepted 10 October 2013

Academic Editor: Chunyi Zhi

Copyright (C) 2013 U. Hashim et al. This is an open access article distributed under the Creative Commons Attribution License, which permits unrestricted use, distribution, and reproduction in any medium, provided the original work is properly cited.

Development and fabrication of single-walled carbon nanotube (SWNT) based pH sensor were reported. The precise alignment of individual SWNT using dielectrophoresis method between the two microgap electrodes was conducted, and the effects of precise alignment of individual SWNT on impedance, long term stability, and capacitance of the sensor were studied. The $\mathrm{pH}$ sensor was fabricated using conventional photolithography and wet etching process. The impedance values were found to decrease in the order of distilled water $>\mathrm{pH} 10>\mathrm{pH} 5>\mathrm{pH} 3>$ air. Without the alignment of SWNT, the capacitances values decreased with increasing of $\mathrm{pH}$ values at low frequency. All the impedance and capacitance results were highly repeatable.

\section{Introduction}

Since the discovery of carbon nanotube (CNT), it has been used to develop new generation of sensor due to its many excellent properties [1]. For CNT, it is divided into two major categories which are single-walled carbon nanotubes (SWNTs) and multiwalled carbon nanotubes (MWNTs). An SWNT consists of single layer of graphene closed at both ends as compared to MWNTs which are made up from multilayers of graphene $[2,3]$. CNTs show high potential in wide range of application in nanoelectronics and biomedical sensors based on the increasing number of publication every year. Precise alignment of individual SWNT between electrodes is essential for practical electronic applications. The popularity of CNTs has facilitated a wide range of applications such as field-effect transistors [4-8], chemical and biological sensors $[9,10]$, scanning probe microscopy tips [11-13], and field emitters $[14,15]$. However, the challenge to align the CNT at desired positions between electrodes is still present until now [16-19]. Several methods have been used to place CNTs, but they have some disadvantages. Position and distribution of CNT between electrodes were difficult to be controlled when spin coating was used $[7,20]$. High temperatures are needed when CNTs are synthesized directly and show other drawbacks as well such as poor selectivity of growth and noncompatibility of device at high temperatures [21-23]. Another technique is to deposit CNTs manually. However, it is difficult to grip a CNT by the manipulator since CNT is in nanosize [24]. Dielectrophoresis, on the other hand, has been proven as a simple and quick method to align CNTs in the desired position. It is because this technique can be easily carried out at room temperature using low voltages.

In this study, individual functionalized SWNT was aligned using dielectrophoresis method between the two gold electrodes. The gold electrodes were fabricated on silicon substrate using photolithography and wet etching. Scanning electron microscopy (SEM) and field emission scanning electron microscopy (FESEM) were used to investigate the alignment of individual functionalized SWNT between the two gold electrodes. The device was used as $\mathrm{pH}$ sensor and tested using three different $\mathrm{pH}$ buffer solutions, and the conductivity, capacitance, and impedance measurement were conducted as well.

\section{Methodology}

2.1. Preparation of Individual SWNTs. The functionalized SWNTs with purity of $>90 \%$ were purchased from 


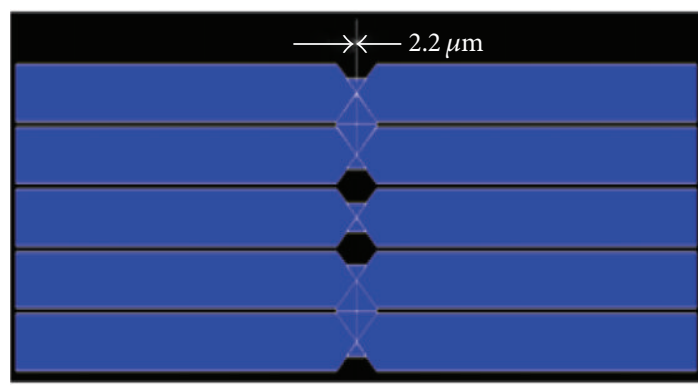

FIGURE 1: Schematic structure of the teeth-like electrode design.

Sigma-Aldrich. The functionalized group attached to SWNTs was carboxylic acid. The functionalized SWNTs were dispersed in IPA solution using ultrasonic process for $30 \mathrm{~min}$ to debundle functionalized SWNTs into individual SWNT.

2.2. Fabrication of $p H$ Sensor. In this research, the normal transparency sheets were used as the material for the photomasks to fabricate the $\mathrm{pH}$ sensor. The photomasks were designed using AutoCAD and printed onto transparency sheets. Figure 1 shows the design of gold electrodes which is similar to a teeth structure with the width of $2.2 \mu \mathrm{m}$ between them.

Figure 2 shows the fabrication flow of $\mathrm{pH}$ sensor using conventional photolithography method. The silicon wafer was first cleaned thoroughly using acetone before the deposition of silicon oxide. The wafer was coated with a $270 \AA$ thick thermal-grown $\mathrm{SiO}_{2}$ as an insulating layer using Modulab dry oxidation furnace. Then, a layer of $\mathrm{Ti}$ with thickness of $100 \mathrm{~nm}$ as an adhesion material and a layer of $\mathrm{Au}$ with thickness of $200 \mathrm{~nm}$ as an electrode material were coated on the wafer surface using thermal evaporator (Auto 306). Then, a layer of positive photoresist (PR) was coated onto the silicon surface using a Shipley S1813 Resist Spin Coater. Soft bake was conducted for $90 \mathrm{~s}$ to remove moisture after PR was coated onto the silicon surface. The pattern from the photomask was then transferred onto the wafer using MIDAS MDA-400M mask aligner exposure system with ultraviolet wavelength of $365 \mathrm{~nm}$ and an exposure time of $10 \mathrm{~s}$. Next, the RD6 developer solution (Futurrex) was used to develop the pattern after the UV exposure and continued by the hard bake process for $90 \mathrm{~s}$. The unwanted pattern which was not exposed to UV was etched away using aqua regia etchant. The times for Au and $\mathrm{Ti}$ etching were $30 \mathrm{~s}$ and $60 \mathrm{~s}$, respectively. Aqua regia solution was prepared by mixing hydrochloric acid $(\mathrm{HCl})$ and nitric acid $\left(\mathrm{HNO}_{3}\right)$ in a ratio of $4: 1$. The aqua regia was then diluted in distilled (DI) water in the ratio of $1: 2$ to reduce the concentration of the pure aqua regia and to avoid the pattern to be destroyed. Finally, the PR was stripped using the acetone solution.

2.3. Alignment of Individual SWNT. Figure 3(a) shows the configuration of the experimental system for the dielectrophoresis of SWNT's alignment. A function generator (Agilent Technologies 81150A) was used to generate AC signal
TABLE 1: SWNT's alignment parameters.

\begin{tabular}{lcc}
\hline Device no. & AC voltage (peak-to-peak) & Frequency $(\mathrm{MHz})$ \\
\hline 1 & 1 & 10 \\
2 & 1 & 20 \\
3 & 5 & 10 \\
4 & 5 & 20 \\
\hline
\end{tabular}

source and it was connected to the Au electrodes through two metal probes. The voltage (peak-to-peak) across the electrode gap was monitored using an oscilloscope (Agilent Technologies MSO 7054A). After the electrical measurement instrument was set up, $2.0 \mu \mathrm{L}$ of dispersed SWNTs in IPA solution was dropped carefully in the area between the gold electrodes using micropipet onto the electrode gap where the AC electric field was applied. The individual SWNT was aligned slowly due to the dielectrophoretic force that was created in the electric field. Figure 3(b) illustrates that the alignment of individual SWNT between the two gold electrodes was done successfully. The experiment was conducted at room temperature using an applied AC signal with four different values of peak-to-peak voltages, $V_{\mathrm{pp}}$, and frequency, $f$, as shown in Table 1 .

2.4. Characterization. The $\mathrm{pH}$ sensor was examined under high power microscope (HPM). The gold electrodes and the alignment of individual SWNT were analyzed using scanning electron microscopy (SEM; JEOL JSM 6460LA). Energydispersive X-ray spectroscopy (EDX) was used to determine the carbon content in the samples. A dielectric analyzer (Novocontrol) with Windeta software was used to characterize the electrical properties of the dielectrophoresis-aligned SWNT. The electrical characterization for this research was conducted before and after alignment of SWNT between the electrode gaps using various buffer solutions with $\mathrm{pH}$ of 3 , 5 , and 10. Besides, DI water and air were used to test the $\mathrm{pH}$ sensitivity as well. Also, $1 \mathrm{~Hz}-100 \mathrm{MHz}$ of frequency with constant $0.5 \mathrm{~V}$ of $\mathrm{AC}$ voltage were applied to measure the impedance and capacitance values for different $\mathrm{pH}$ values. The results were obtained from the dielectric analyzer and plotted into graphs. From the plotted graph, a comparison of capacitance and impedance will be made for before and after CNT alignment process.

During the $\mathrm{pH}$ measurement process, solutions were dropped carefully using micro pipet onto the aligned SWNT between the electrode gaps. After each value of the $\mathrm{pH}$ solutions was tested, the sample was cleaned with DI water and filter paper. The blower was used to dry the sample and to make sure that there was no dust on the sample. Sample was kept stationary with the probe needle location to avoid inaccurate results. Furthermore, sample was tested without any vibration or noisy environment to avoid poor results.

\section{Results and Discussion}

3.1. Characterization of $p H$ Sensor. The morphology of gold electrodes was investigated using HPM and the image was shown in Figures 4(a) and 4(b) which shows an enlarged 

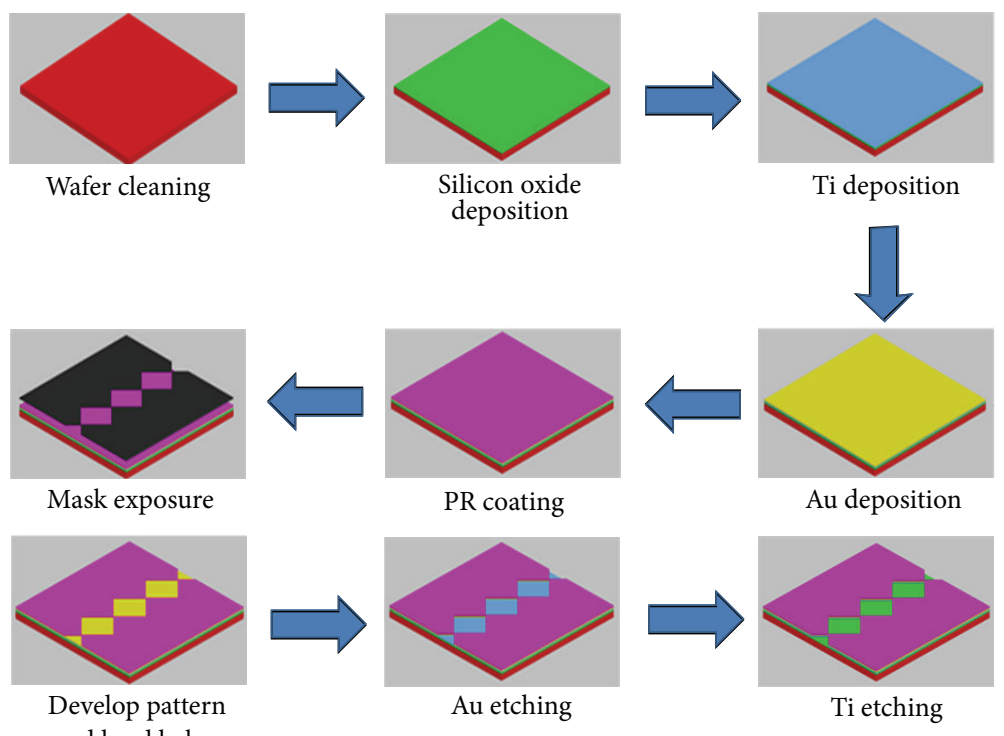

Mask exposure

PR coating

Au deposition
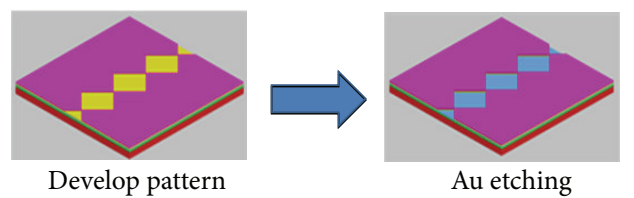

Au etching

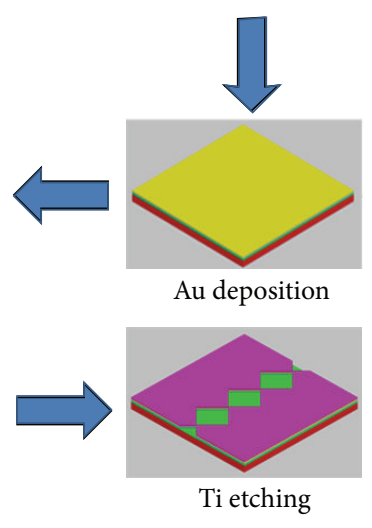

and hard bake

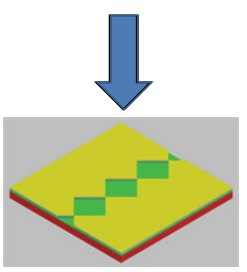

PR cleaning

FIGURE 2: Fabrication process of the gold electrodes.

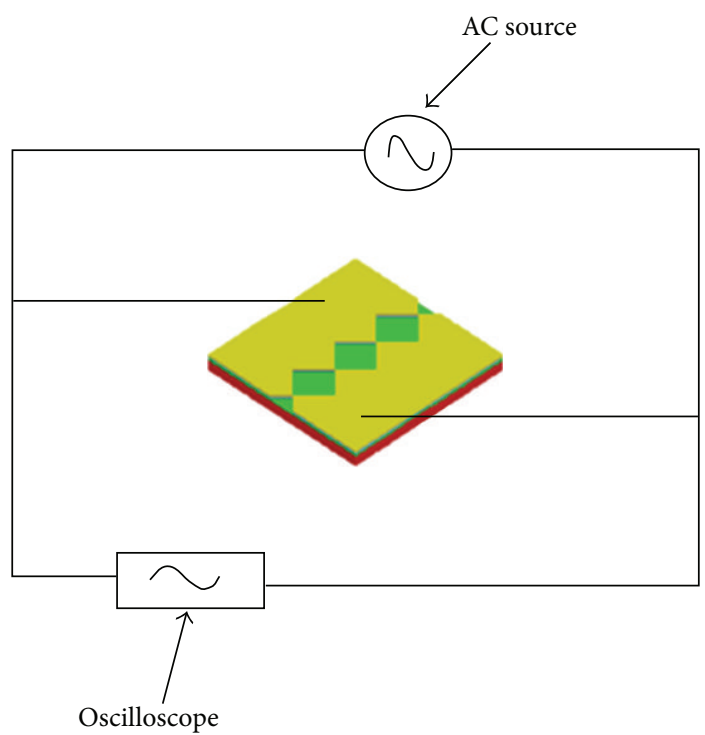

(a)

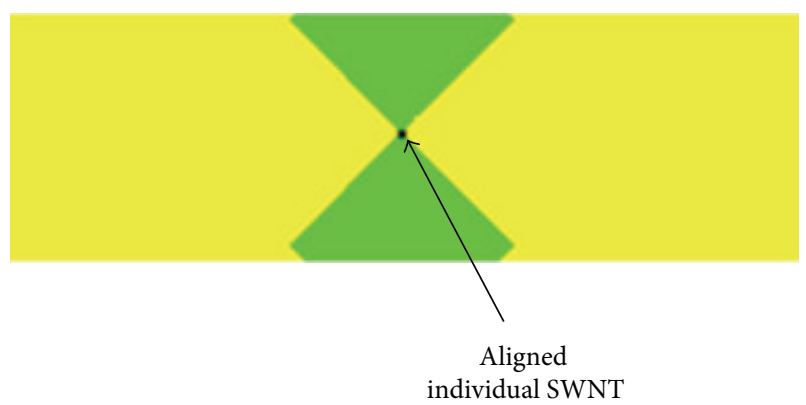

(b)

FIgURE 3: (a) Experimental setup for dielectrophoresis of the CNTs. (b) Schematic diagram of the SWNT alignment.

SEM image of teeth-like gold electrodes of $\mathrm{pH}$ sensor under SEM observation. It is noticed that the distance between two gold electrodes was increased to $29.6 \mu \mathrm{m}$ from the designed value of $2.2 \mu \mathrm{m}$ due to the overetching process of gold electrodes using aqua regia solution. The measured value was the smallest distance that was achieved in this work. The shape of teeth-like structure of gold electrodes was remained the same as designed structure and able to provide a good platform for the alignment of individual SWNT. 


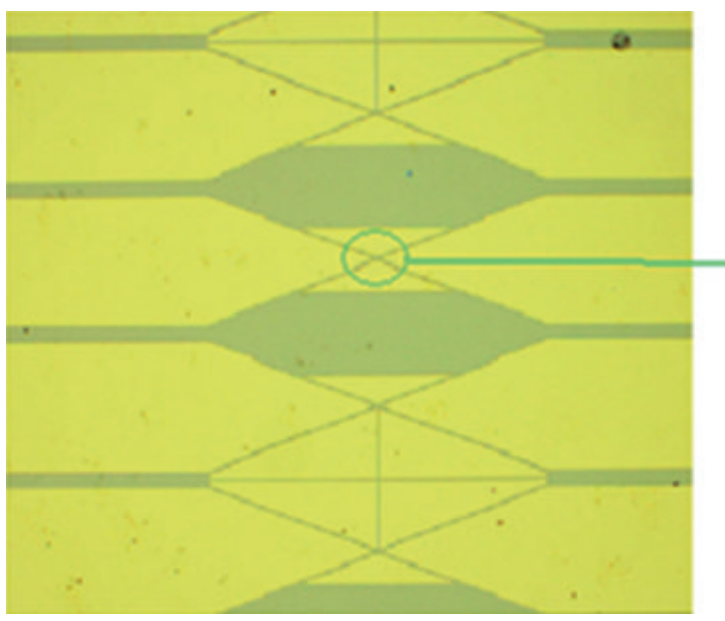

(a)

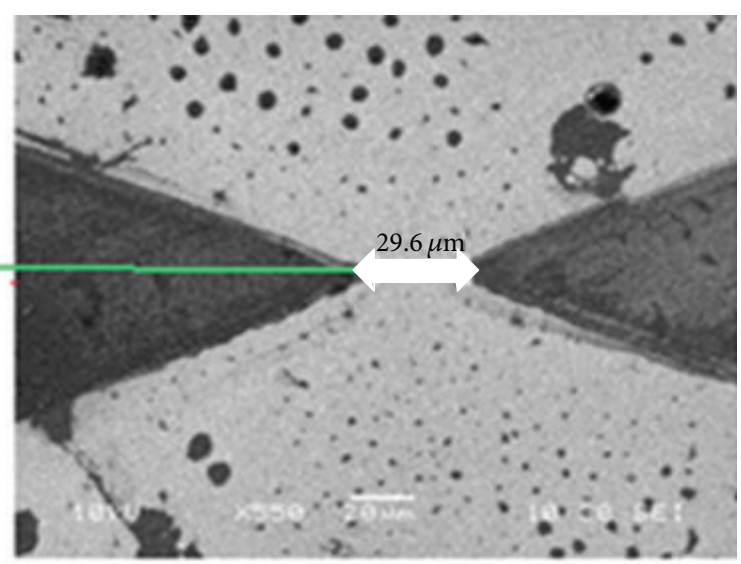

(b)

Figure 4: (a) The HPM image of gold electrodes. (b) An enlarged SEM image of the fabricated gold electrodes.

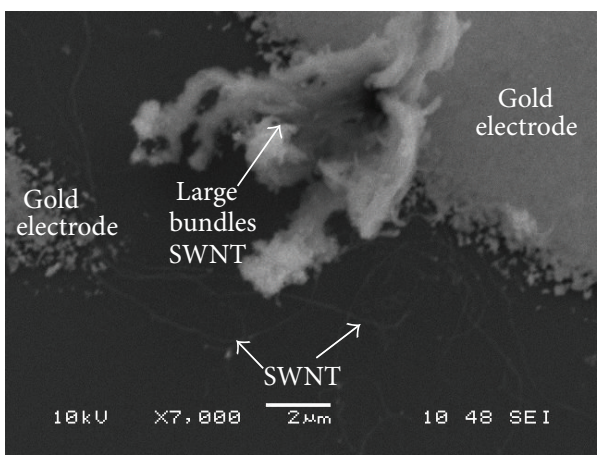

(a)

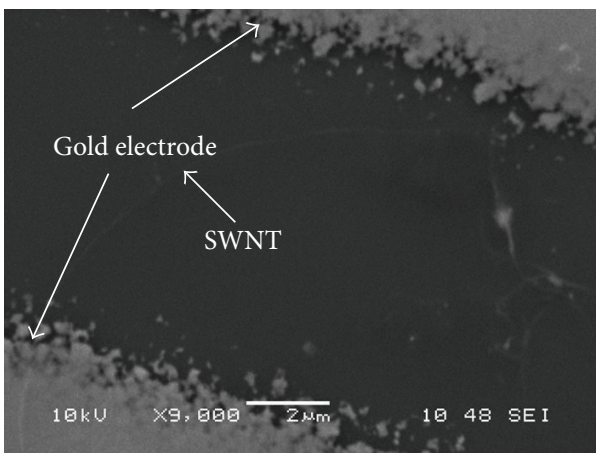

(c)

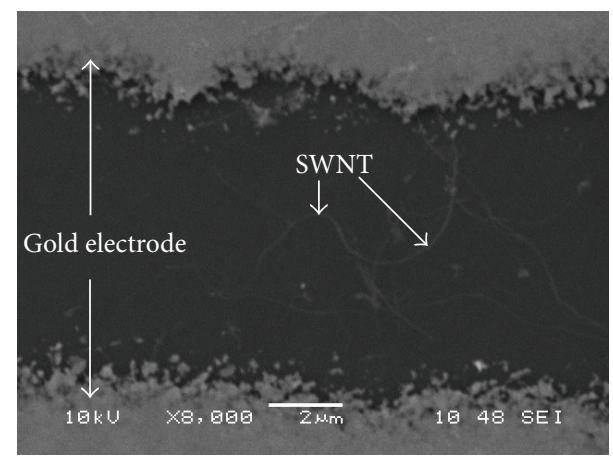

(b)

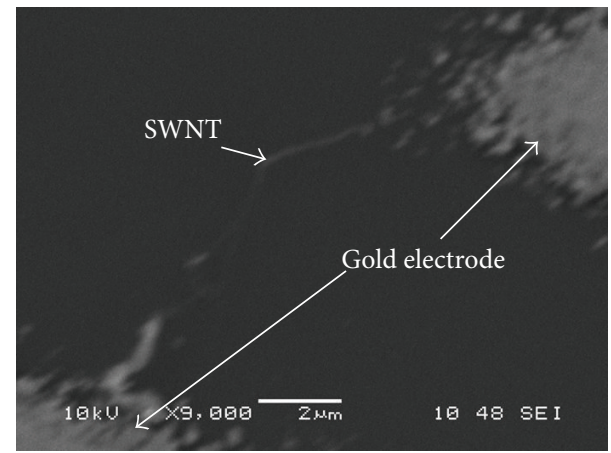

(d)

Figure 5: SEM images of SWNTs' alignment. (a) 1 V, 10 MHz. (b) 1 V, 20 MHz. (c) 5 V, 10 MHz. (d) 5 V, 20 MHz.

3.2. Investigation of Alignment of Individual SWNT. Figure 5 shows the SEM images of the deposited SWNT onto the substrates after being aligned using dielectrophoresis method. In Figure 5(a), large bundles of SWNT were not aligned successfully and accumulated at one of the gold electrodes because the functionalized SWNTs were not dispersed successfully before dielectrophoresis. There were some individual SWNTs that were observed from Figures 5(b)-5(d) between the two gold electrodes, but the alignment was not successful as well.
It is because the SWNT was not aligned straight connecting the two gold electrodes. The quality of aligned SWNTs was influenced by the voltage applied and frequency used during the dielectrophoresis process. Therefore, the voltage and the frequency were set at different values in order to obtain the best parameter to align individual SWNT with the right position (Table 1).

$5 \mathrm{~V}$ peak-to-peak and $20 \mathrm{MHz}$ were found as the best parameters for the alignment of individual SWNT between 


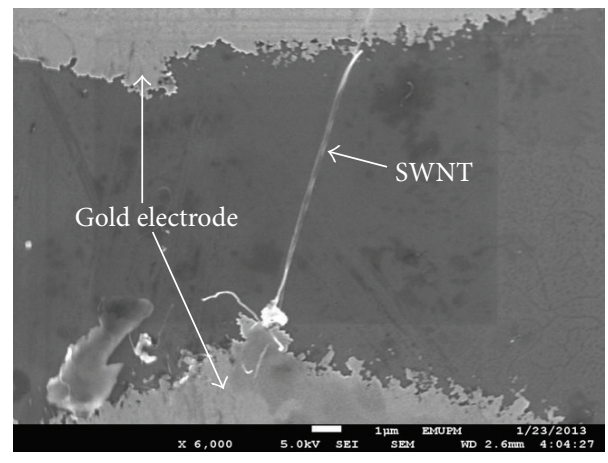

FIGURE 6: FESEM result of individual SWNT aligned at $5 \mathrm{~V}$ peakto-peak and $20 \mathrm{MHz}$ in dielectrophoresis process.

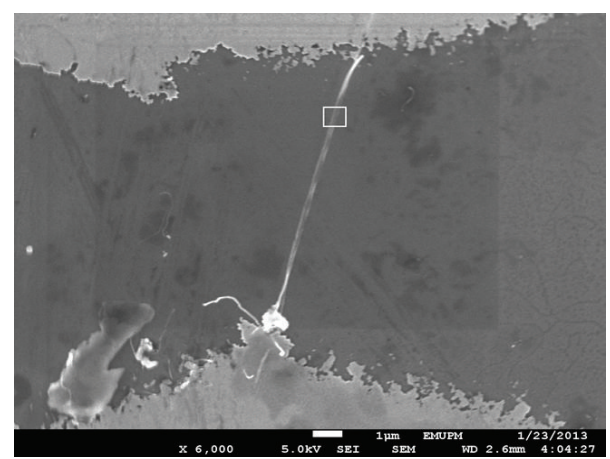

FIGURE 7: EDX analysis at marked spot for individual SWNT aligned using $5 \mathrm{~V}$ peak-to-peak and $20 \mathrm{MHz}$.

TABLE 2: Elements and percentage of weight.

\begin{tabular}{lc}
\hline Element & Weight (\%) \\
\hline $\mathrm{C}$ & 36.30 \\
$\mathrm{O}$ & 10.23 \\
$\mathrm{Si}$ & 53.47 \\
\hline Total & 100.00 \\
\hline
\end{tabular}

the two gold electrodes as shown in Figure 6. The individual SWNT was successfully aligned straight connecting the two gold electrodes and it is rarely reported in the literature. This position facilitated the movement of electron, and therefore, the sensitivity of $\mathrm{pH}$ sensor was greatly improved. When AC current was applied, the electric field was created and induced the dielectrophoretic force $[25,26]$. The individual SWNT was aligned slowly in the presence of this force until the desired position was achieved.

The EDX was analyzed at the marked spot as shown in Figure 7 and the elements weight percentages were shown in Table 2. The EDX result shows that carbon was obtained as major element of $54.30 \%$ as compared to oxygen of $11.49 \%$ and silicon of $34.21 \%$. The highest weight percentages of carbon content were due to the presence of SWNT.

\subsection{Electrical Characterization}

3.3.1. Impedance Results. Impedance results of the aligned individual SWNT were drawn and presented in Figure 8.

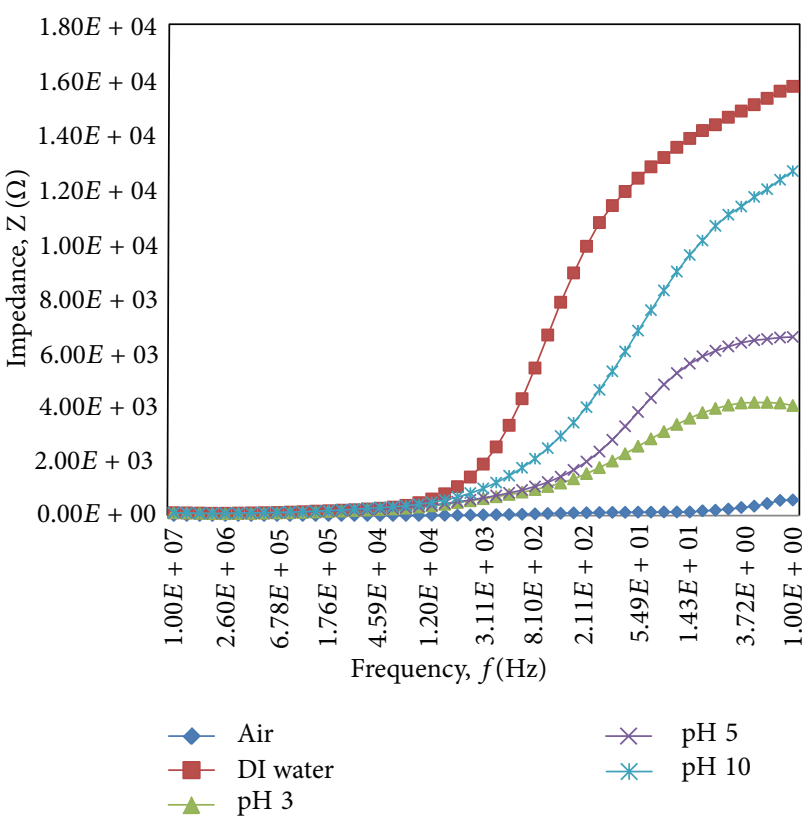

FIGURE 8: Impedance-frequency plot for after SWNT is aligned.

It is observed that the impedance values decreased in the following order of DI water $>\mathrm{pH} 10>\mathrm{pH} 5>\mathrm{pH} 3>$ air. In Figure 8 , when $1 \mathrm{~Hz}$ of frequency was used, the highest value of impedance was obtained for DI water at $15726 \Omega$ as compared to air, buffer solution with $\mathrm{pH} 3, \mathrm{pH} 5$, and $\mathrm{pH} 10$ with value of $570 \Omega, 4028.6 \Omega, 6540.9 \Omega$, and $12617 \Omega$, respectively. It is because DI water does not contain any positive or negative charge as compared to the buffer solutions to facilitate the current flow which lower the impedance values. When buffer solutions were dropped onto the SWNT, hydrogen $\left(\mathrm{H}^{+}\right)$and hydroxide $\left(\mathrm{OH}^{-}\right)$ions can accept or donate electron to the carboxyl groups of functionalized SWNTs [27]. Buffer solution with $\mathrm{pH} 10$ demonstrated the higher impedance value than buffer solutions with $\mathrm{pH} 3$ and 5 due to the presence of $\mathrm{OH}^{-}$which donated electron to the p-orbital of the SWNT and caused the effect that no positive hole was created in the SWNT [28]. Thus, the conductance was decreased. However, the high concentration of $\mathrm{H}^{+}$existed in buffer solutions with $\mathrm{pH}$ of 3 and 5 caused the opposite effects and increased the conductance of SWNT. The conductance of SWNT was changed which contributed to the donate/accept electron process [28].

3.3.2. Long Term Stability with Buffer Solution. A stable pH sensor should be able to demonstrate its sensitivity for a long period of time. Thus, the SWNT based $\mathrm{pH}$ sensor must be tested for its long term stability because $\mathrm{pH}$ sensor is working in aqueous environment which is always affected by many factors. The SWNT based pH sensor was tested every $24 \mathrm{~h}$ for seven consecutive days under the exact same experimental environments. The recorded impedances of the sensor for $\mathrm{pH} 3, \mathrm{pH} 5$, and $\mathrm{pH} 10$ during this period were shown in Figure 9(a). The impedance values are relatively stable and this indicates that the SWNT based $\mathrm{pH}$ sensor 


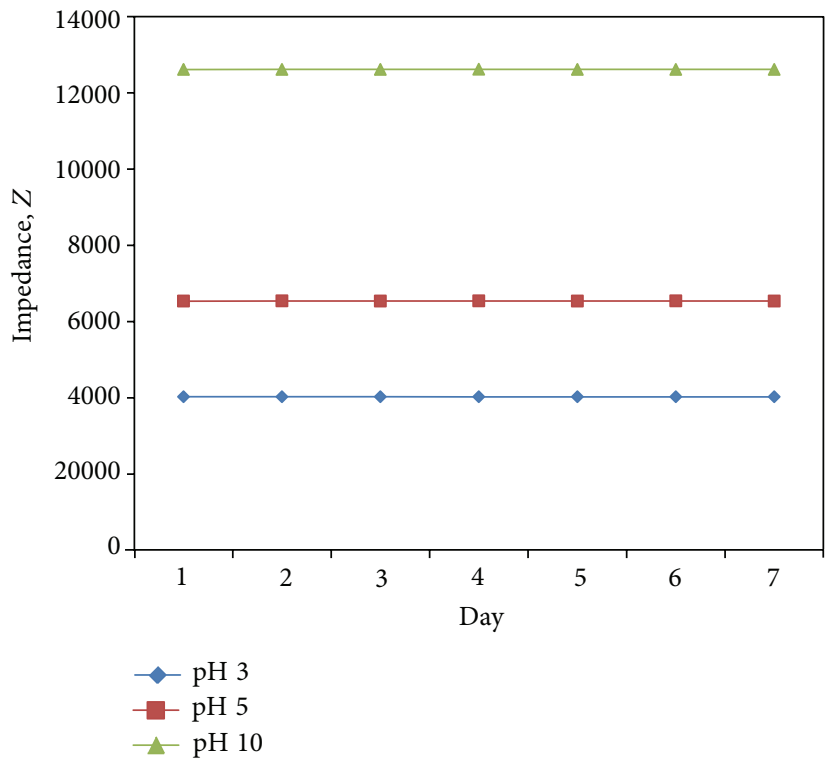

(a)

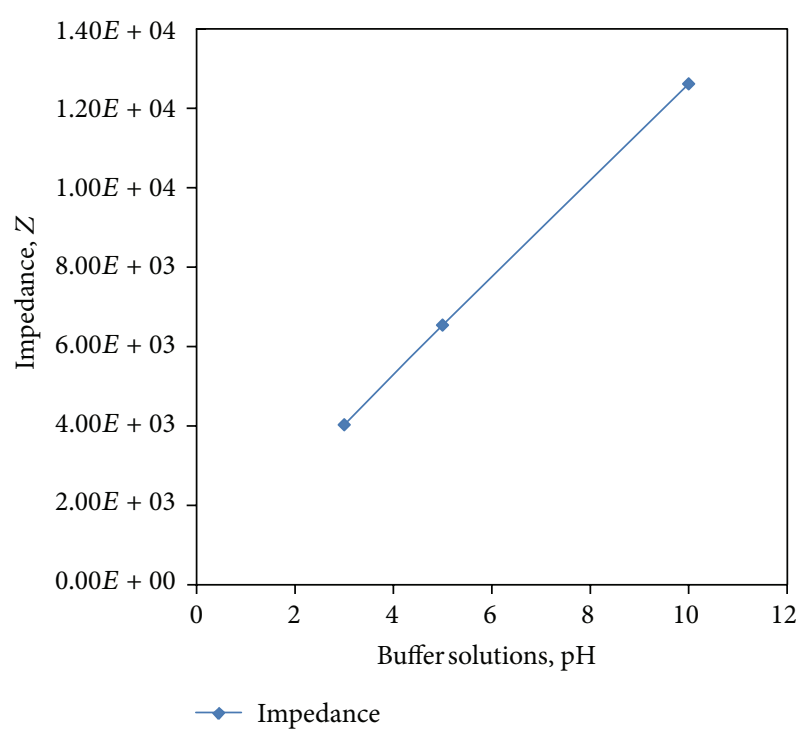

(b)

FIGURE 9: Impedance variation of one sensor in $\mathrm{pH}$ buffer solutions in seven consecutive days.

remained sensitive to the buffer solutions after long period of time. To study the interaction between the impedance and the $\mathrm{pH}$ value, the obtained values from Figure 9(a) were replotted and presented in Figure 9(b). From the plot, we can see clearly that the SWNT based pH sensor was able to work consistently within seven days to give linear interaction between the impedance and the $\mathrm{pH}$ values.

3.3.3. Capacitance Results. For a capacitor, it generates a capacitance value when an insulator known as dielectric exists in between the two electrodes. Before SWNT was aligned between the two gold electrodes, the device can be considered as a capacitive sensor. However, after the alignment of individual functionalized SWNT, the device created zero capacitance values because the SWNT is a semiconductor material. To study the capacitance effect, buffer solutions were dropped onto a $\mathrm{pH}$ sensor without the alignment of SWNT. Figure 10 shown the capacitancefrequency plot. It is clearly shows that the capacitances values decreased with increasing of $\mathrm{pH}$ values at low frequency. The capacitance values recorded for buffer solutions with $\mathrm{pH} 3, \mathrm{pH} 5$, and $\mathrm{pH} 10$ were $12.6 \mu \mathrm{F}, 16.4 \mu \mathrm{F}$, and $39.5 \mu \mathrm{F}$, respectively. The conductivity is proportional to the current that flows between the two gold electrodes. For current to flow, ions must be present in solution to carry the charge from one electrode to another electrode. Increasing the number of ions in solution will increase the amount of charge that can be carried between two electrodes and thus increase the conductivity. Another factor in conductivity measurements is that not all ions can carry charge (conduct electricity) equally. Hydrogen $\left(\mathrm{OH}^{+}\right)$and hydroxide $\left(\mathrm{OH}^{-}\right)$are very good charge carriers because they are unique and can move in solution very rapidly. It is well known that the molar conductivity

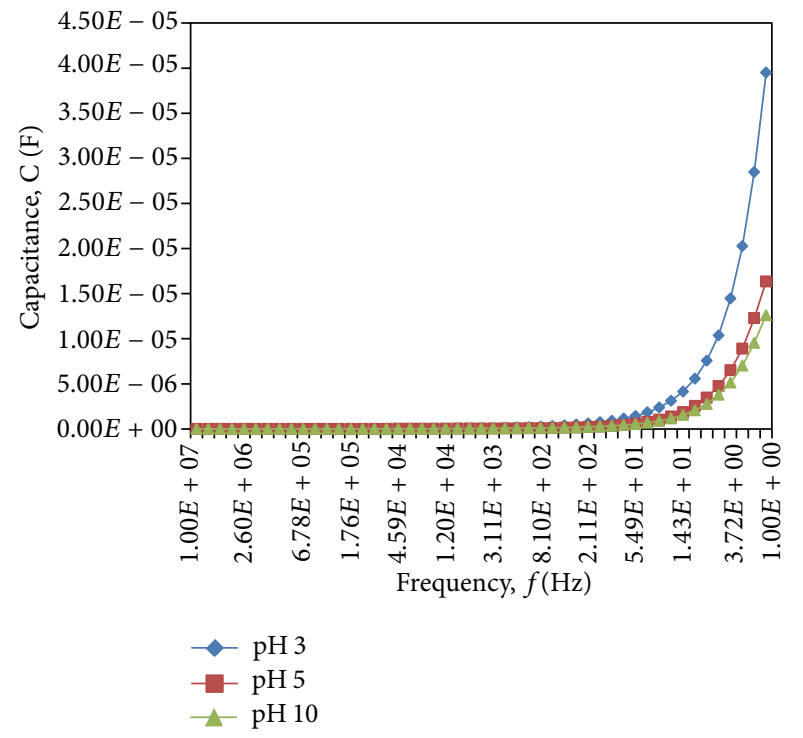

FIgURE 10: Capacitance variation of $\mathrm{pH} 3, \mathrm{pH}$ 5, and $\mathrm{pH} 10$ without alignment of SWNT.

of hydrogen $\left(\mathrm{H}^{+}\right)$ions is $0.3498 \mathrm{~mol}^{-1} \mathrm{~cm}^{-1}$ which is much higher than hydroxide $\left(\mathrm{OH}^{-}\right)$of $0.1986 \mathrm{~mol}^{-1} \mathrm{~cm}^{-1}$ [29]. Thus, buffer solutions with $\mathrm{pH} 3$ and $\mathrm{pH} 5$ demonstrated higher molar conductivity than buffer solution with $\mathrm{pH} 10$. Therefore, when the molar conductivity is high, the capacitance value is low.

\section{Conclusions}

We have fabricated the SWNT based $\mathrm{pH}$ sensor using low cost and simple photolithography and wet etching process. 
Individual SWNT was aligned successfully between the two teeth-like gold electrodes. $5 \mathrm{~V}$ peak-to-peak and $20 \mathrm{MHz}$ were the optimum voltage and frequency to align the individual SWNT using dielectrophoresis method. The impedance showed a linear response to the $\mathrm{pH}$ values of 3,5 , and 10 . As the $\mathrm{pH}$ was increased, the impedance increased as well due to the donate/accept electron activities that happened which were induced by hydrogen $\left(\mathrm{H}^{+}\right)$and hydroxide $\left(\mathrm{OH}^{-}\right)$ with carboxyl groups of functionalized SWNT. Without the alignment of SWNT, low capacitance values were measured for buffer solutions with $\mathrm{pH} 3$ and 5 which is attributed to the higher molar conductivity of hydrogen $\left(\mathrm{H}^{+}\right)$than hydroxide $\left(\mathrm{OH}^{-}\right)$. All the impedance and capacitance results showed here were repeatable. Although SWNT based pH sensor is still at its early research stages, we believe that the performance could be greatly improved by using advanced nanomaterial such as graphene.

\section{Acknowledgments}

The authors wish to thank Universiti Malaysia Perlis (UniMAP) Grant MOA Sciencefund 050-01-15-SF1009 and FRGS for giving the opportunities to do this research in the Micro \& Nano Fabrication Clean room. The appreciation also goes to all the team members in the Institute of Nano Electronic Engineering (INEE) especially Nano Biochip Research Group members.

\section{References}

[1] N. Sinha, J. Ma, and J. T. W. Yeow, "Carbon nanotube-based sensors," Journal of Nanoscience and Nanotechnology, vol. 6, no. 3, pp. 573-590, 2006.

[2] S. Iijima, "Helical microtubules of graphitic carbon," Nature, vol. 354, pp. 56-58, 1991.

[3] S. Iijima and T. Ichihashi, "Single-shell carbon nanotubes of 1nm diameter," Nature, vol. 363, pp. 603-605, 1993.

[4] H. Li, Q. Zhang, and J. Li, "Carbon-nanotube-based singleelectron/hole transistors," Applied Physics Letters, vol. 88, no. 1, Article ID 013508, 2006.

[5] A. Javey, J. Guo, D. B. Farmer et al., "Carbon nanotube fieldeffect transistors with integrated ohmic contacts and high- $\kappa$ gate dielectrics," Nano Letters, vol. 4, no. 3, pp. 447-450, 2004.

[6] R. Martel, T. Schmidt, H. R. Shea, T. Hertel, and P. Avouris, "Single- and multi-wall carbon nanotube field-effect transistors," Applied Physics Letters, vol. 73, no. 17, pp. 2447-2449, 1998.

[7] S. J. Wind, J. Appenzeller, R. Martel, V. Derycke, and P. Avouris, "Vertical scaling of carbon nanotube field-effect transistors using top gate electrodes," Applied Physics Letters, vol. 80, no. 20, pp. 3817-3819, 2002.

[8] S. J. Tans, A. R. M. Verschueren, and C. Dekker, "Roomtemperature transistor based on a single carbon nanotube," Nature, vol. 393, pp. 49-52, 1998.

[9] J. Kong, N. R. Franklin, C. Zhou et al., "Nanotube molecular wires as chemical sensors," Science, vol. 287, pp. 622-625, 2000.

[10] P. G. Collins, K. Bradley, M. Ishigami, and A. Zettl, "Extreme oxygen sensitivity of electronic properties of carbon nanotubes," Science, vol. 287, pp. 1801-1804, 2000.
[11] H. Dai, J. H. Hafner, A. G. Rinzler, D. T. Colbert, and R. E. Smalley, "Nanotubes as nanoprobes in scanning probe microscopy," Nature, vol. 384, pp. 147-150, 1996.

[12] E. S. Snow, P. M. Campbell, and J. P. Novak, "Single-wall carbon nanotube atomic force microscope probes," Applied Physics Letters, vol. 80, no. 11, pp. 2002-2004, 2002.

[13] J. H. Hafner, C. L. Cheung, and C. M. Lieber, "Growth of nanotubes for probe microscopy tips," Nature, vol. 398, pp. 761762, 1999.

[14] B. Ulmen, V. K. Kayastha, A. Deconinck, J. Wang, and Y. K. Yap, "Stability of field emission current from various types of carbon nanotube films," Diamond and Related Materials, vol. 15, no. 2-3, pp. 212-216, 2006.

[15] A. Pandey, A. Prasad, J. Moscatello, B. Ulmen, and Y. K. Yap, "Enhanced field emission stability and density produced by conical bundles of catalyst-free carbon nanotubes," Carbon, vol. 48, no. 1, pp. 287-292, 2010.

[16] D. Ding, Z. Chen, S. Rajaputra, and V. Singh, "Hydrogen sensors based on aligned carbon nanotubes in an anodic aluminum oxide template with palladium as a top electrode," Sensors and Actuators B, vol. 124, no. 1, pp. 12-17, 2007.

[17] A. M. Fennimore, T. D. Yuzvinsky, W.-Q. Han, M. S. Fuhrer, J. Cumings, and A. Zetti, "Rotational actuators based on carbon nanotubes," Nature, vol. 424, pp. 408-410, 2003.

[18] R. H. Baughman, C. Cui, A. A. Zakhidov et al., "Carbon nanotube actuators," Science, vol. 284, pp. 1340-1344, 1999.

[19] A. R. Hall, M. R. Falvo, R. Superfine, and S. Washburn, "A self-sensing nanomechanical resonator built on a single-walled carbon nanotube," Nano Letters, vol. 8, no. 11, pp. 3746-3749, 2008.

[20] A. Bachtold, P. Hadley, T. Nakanishi, and C. Dekker, "Logic circuits with carbon nanotube transistors," Science, vol. 294, pp. 1317-1320, 2001.

[21] A. Javey, M. Shim, and H. Dai, "Electrical properties and devices of large-diameter single-walled carbon nanotubes," Applied Physics Letters, vol. 80, no. 6, pp. 1064-1066, 2002.

[22] X. Liu, C. Lee, C. Zhou, and J. Han, "Carbon nanotube fieldeffect inverters," Applied Physics Letters, vol. 79, no. 20, pp. 33293331, 2001.

[23] B. S. Oh, Y.-S. Min, E. J. Bae et al., "Fabrication of suspended single-walled carbon nanotubes via a direct lithographic route," Journal of Materials Chemistry, vol. 16, no. 2, pp. 174-178, 2006.

[24] T. Fukuda, F. Arai, and L. Dong, "Assembly of nanodevices with carbon nanotubes through nanorobotic manipulations," Proceedings of the IEEE, vol. 91, no. 11, pp. 1803-1818, 2003.

[25] M. Dimaki and P. Bøggild, "Dielectrophoresis of carbon nanotubes using microelectrodes: a numerical study," Nanotechnology, vol. 15, no. 8, pp. 1095-1102, 2004.

[26] S. Raychaudhuri, S. A. Dayeh, D. Wang, and E. T. Yu, "Precise semiconductor nanowire placement through dielectrophoresis," Nano Letters, vol. 9, no. 6, pp. 2260-2266, 2009.

[27] S. Takeda, M. Nakamura, A. Ishii et al., "A pH sensor based on electric properties of nanotubes on a glass substrate," Nanoscale Research Letters, vol. 2, no. 4, pp. 207-212, 2007.

[28] D. Lee and T. Cui, "PH -dependent conductance behaviors of layer-by-layer self-assembled carboxylated carbon nanotube multilayer thin-film sensors," Journal of Vacuum Science and Technology B, vol. 27, no. 2, pp. 842-848, 2009.

[29] G. M. Barrow, "The nature of hydrogen bonded ion-pairs: the reaction of pyridine and carboxylic acids in chloroform," The Journal of the American Chemical Society, vol. 78, no. 22, pp. 5802-5806, 1956. 

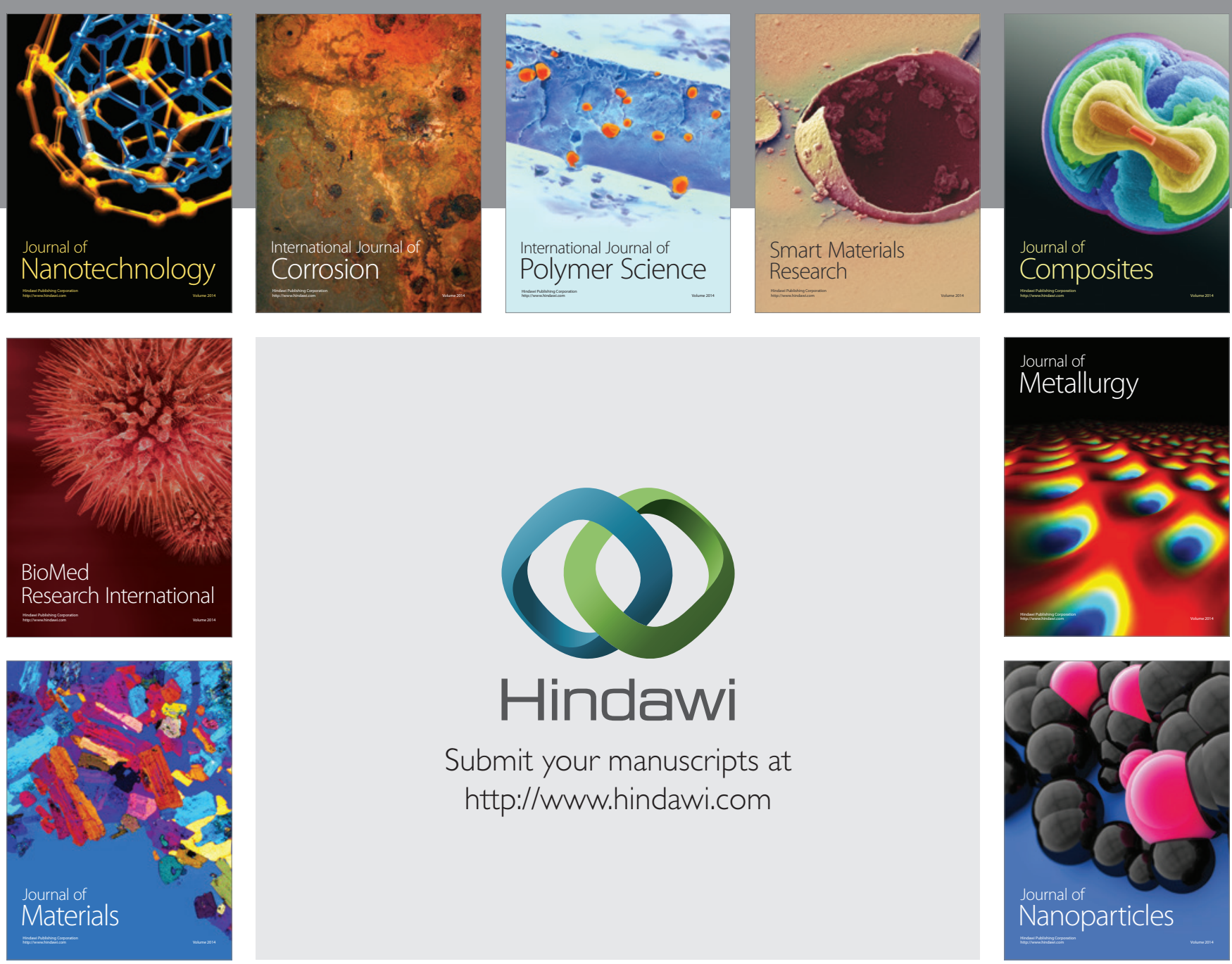

Submit your manuscripts at http://www.hindawi.com
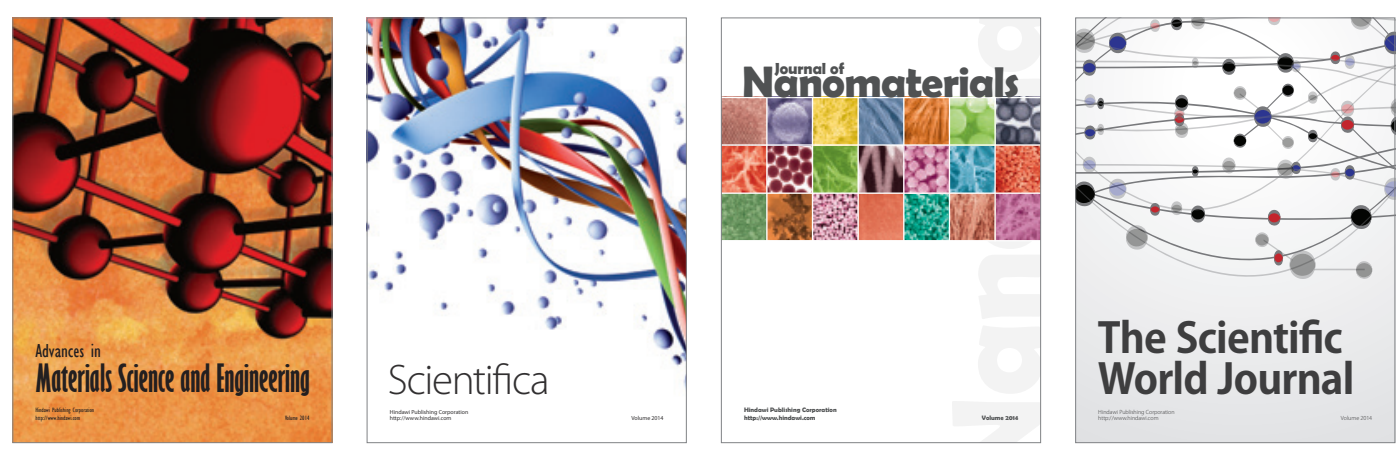

\section{The Scientific World Journal}
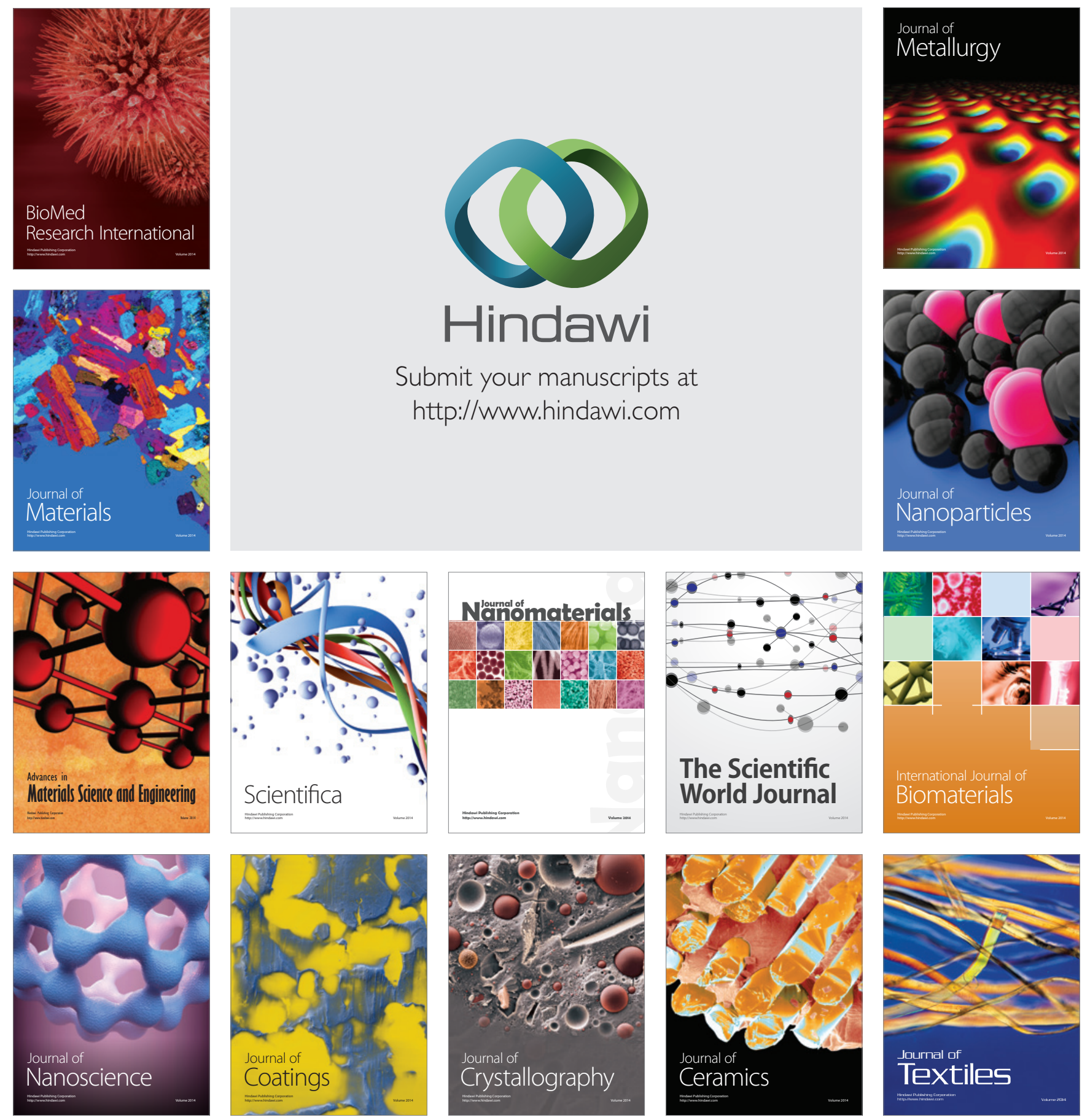